\title{
Primordial and Primary Preventions of Thyroid Disease
}

\author{
Fereidoun Azizi, ${ }^{1}$ Ladan Mehran, ${ }^{1}$ Farhad Hosseinpanah, ${ }^{2}$ Hossein Delshad, ${ }^{2}$ and Atieh Amouzegar ${ }^{1, *}$ \\ ${ }^{1}$ Endocrine Research Center, Research Institute for Endocrine Sciences, Shahid Beheshti University of Medical Sciences, Tehran, IR Iran \\ ${ }^{2}$ Obesity Research Center, Research Institute for Endocrine Sciences, Shahid Beheshti University of Medical Sciences, Tehran, IR Iran \\ "Corresponding author: Atieh Amouzegar, Assistant Professor of Internal Medicine and Endocrinology, Endocrine Research Center, Research Institute for Endocrine Sciences, \\ Shahid Beheshti University of Medical Sciences, Tehran, IR Iran, P.O. Box: 19395-4763. Tel: +98-2122432503, Fax: +98-2122402463, E-mail: amouzegar@endocrine.ac.ir
}

Received 2017 April 05; Revised 2017 July 09; Accepted 2017 August 14.

\begin{abstract}
Background: Primordial and primary preventions of thyroid diseases are concerned with avoiding the appearance of risk factors, delaying the progression to overt disease, and minimizing the impact of illness.

Summary: Using related key words, 446 articles related to primordial and primary, preventions of thyroid diseases published between 2001-2015 were evaluated, categorized and analyzed. Prevention and elimination of iodine deficiency are major steps that have been successfully achieved and maintained in many countries of the world in last 2 decades. Recent investigations related to the effect of cigarette smoking, alcohol consumption, and autoimmunity in the prevention of thyroid disorders have been reviewed. Conclusions: The cornerstone for successful prevention of thyroid disease entails timely implementation of its primordial and primary preventions, which must be highly prioritized in related health strategies by health authorities.
\end{abstract}

Keywords: Prevention, Thyroid Disease, Hyperthyroidism, Hypothyroidism, Thyroid Cancer, Pregnancy and Thyroid, Iodine Deficiency, Smoking

\section{Introduction}

Physicians have long dedicated themselves to the promotion of health and prevention of disease in mankind. Rabi-Ebn-Ahmad Akhvaini, a Persian scholar, defined medicine as a profession that maintains health status, when disturbed by disease and restores health in man, using knowledge and practice (1). Preventive medicine is, hence, concerned with precluding the appearance of risk factors, delaying the progression to overt disease, and decreasing the impact of illness. By definition, there are 4 distinct types of prevention in different phases of disease (2). Primordial prevention is the maintenance and promotion of health in the community by averting the appearance of risk factors of a disease. Primary prevention is performed by controlling or reducing risk factors to prevent overt disease in previously healthy individuals. Secondary prevention is avoiding the progression of latent or mild illness to more advanced stages (presence of physiological abnormality without sign or symptom manifestation). Tertiary prevention is the optimization of medical care and management to improve an already established disease and avoidance of complications and disabilities (presence of sign and symptoms) (3). Quaternary prevention is a newer concept that refers to actions taken to identify a patient or a population at risk of overmedicalisation to protect them from invasive medical interventions and provide them with care procedures that are ethically acceptable. Approaches to prevention overlap and merge, yet all levels are equally important and complementary. Primordial and primary preventions are related to health of the whole population, while secondary and tertiary preventions are generally focused on people who already have signs of disease.

During the past decades, much success has been achieved in controlling several infectious and noncommunicable diseases in many high-income countries, and some developing countries (4), however, there is limited data of comprehensively designed studies on prevention of thyroid disorders.

In the realm of thyroid disease, prevention of iodine deficiency disorders (IDD) by adequate iodine nutrition has been recognized and implemented in many parts of the world in the past century (5); this is a classic form of primordial prevention for health promotion and avoidance of iodine deficiency, a known risk factor for goiter, hypothyroidism, mental deficiency, and other manifestations of iodine deficiency disorders (IDD). Preventing common environmental exposures such as perchlorate, thiocyanate, and nitrate are other primordial preventive measures against thyroid disorders; however, evidence for their established role in causing disease is unclear. Understanding and identifying potential risk factors of thyroid autoimmunity to prevent its occurrence is another type of primordial prevention.

Smoking cessation, control of alcohol consumption, and thyroid autoimmunity (positive antibody alone) are 
listed among measures of primary prevention of thyroid disorders.

Therefore, the main question is "What are the effective factors contributing to primordial and primary prevention of thyroid diseases?" Except for prevention of IDD, articles dealing with other aspects of prevention in thyroid disease are scanty (6). Therefore, this research aimed at reviewing the data available on primordial and primary preventions of thyroid disease.

\section{Methods}

The terms "prevention" OR "screening" with either of the following keywords, "iodine", "iodine deficiency", "thyroid", "hypothyroidism”, "hyperthyroidism”, "thyroid nodules", and "thyroid cancer" were used to search Medline for papers published from July 2001 to July 2015. A combination of more general search term usage with additional filtering of articles was applied to include all relevant articles related to the 4 types of prevention in thyroid disease. After reviewing, authors divided the articles into 2 parts: one related to primary and primordial (446 articles) and the other related to secondary and tertiary preventions (2361 articles). We reviewed all abstracts of studies published in both French and English and included those appropriately designed. Two librarians at our institute assisted us in searching for articles. An article had to meet the following criteria to be qualified:

a) Having an appropriate study design of clinical trials, cohort, case control studies, or surveys.

b) Being a scholarly written review article.

c) Having followed guidelines of major international organizations.

d) Making the reviewer aware of authors' names; this was done deliberately to allow the reviewer to include all pertinent studies of initial 446 articles related to primary and primordial preventions; 86 articles fulfilled the abovementioned criteria and were selected for this review, and their results were included in pre-designed tables, from which the data used in this review were extracted.

\subsection{Primordial Prevention of Thyroid Disease}

\subsubsection{Iodine Nutrition}

The best prototype of primordial prevention of thyroid disease is adequate iodine nutrition for prevention of iodine deficiency, which is the most preventable cause of mental retardation. Approximately 1.6 billion people worldwide are at risk of iodine deficiency disorders (IDD).

\subsubsection{Iodine Deficiency Disorders}

The term IDD includes all complications of poor iodine nutrition that can be prevented by ensuring the adequacy of iodine intake (5). Iodine deficiency can result in abortions, stillbirths, motor skill disturbances, mental growth defects, impaired cognitive developments, spastic weakness, and paralysis and it affects the child's learning capacity (lower IQ), deaf-mutism, poor women's health, and thereby affecting the quality of life of communities and economic productivity (Table 1). The most important effects are related to brain functioning of a child, resulting in decrease in IQ. In addition to the above- mentioned disorders, lack of iodine in the diet may cause decline in the socioeconomic status in communities, whose members have insufficient education and inappropriate productivity. Iodine deficiency in livestock may cause a reduction of milk, meat, and wool production from sheep (7). All these sequelae can be avoided, ensuring a continuous supply of iodine to the entire population through salt iodization, a cost effective, inexpensive, and the most suitable method guaranteeing adequate iodine nutrition (8).

Table 1. The Spectrum of Iodine Deficiency Disorders (IDD)

\begin{tabular}{ll}
\hline Period of Life & Disorders \\
\hline Fetus & $\begin{array}{l}\text { Abortions, stillbirths, congenital anomalies, increased } \\
\text { prenatal mortality, endemic cretinism }\end{array}$ \\
\hline Neonate & Neonatal hypothyroidism, mental retardation, goiter \\
\hline Childhood & $\begin{array}{l}\text { Goitre, retarded physical development, overt and } \\
\text { subclinical hypothyroidism, impaired mental function (low } \\
\text { intelligence quotient) }\end{array}$ \\
\hline Adulthood & $\begin{array}{l}\text { Goitre, hypothyroidism spontaneous hyperthyroidism in } \\
\text { the elderly, impaired mental function }\end{array}$ \\
\hline
\end{tabular}

\subsubsection{Iodine Requirement}

Each individual needs only minute amounts of iodine, approximately 150 to 200 microgram daily or a teaspoonful for entire life, to ensure proper synthesis of thyroxin, and regulation of normal growth and development (5).

During pregnancy and lactation, iodine requirement increases and the recommended nutrient intake is set at $250 \mu \mathrm{g}$ of iodine per day (Box 1). Until recently, it was believed that in regions where $\geq 90 \%$ of households had consumed iodized salt for at least 2 years, and the median urinary iodine in school children showed iodine sufficiency, there was no need for iodine supplementation in pregnant and lactating mothers. However, due to low levels of median urinary iodine in these women in some regions with iodine sufficiency, this has been challenged, and the American thyroid association now recommends $150 \mu$ g daily iodine supplementation for pregnant and lactating women. 
In regions without USI or with inadequate iodine supplementation, supplements in the form of daily oral potassium iodide must be provided to meet the requirement of $250 \mu \mathrm{g}$ iodine daily. In special circumstances, $400 \mathrm{mg}$ of iodized oil could be delivered as a single dose (9).

Box 1. Recommended Daily Intakes of Iodine ${ }^{\mathrm{a}}$

\begin{tabular}{l}
\hline Recommended Daily Intakes of Iodine \\
\hline $90 \mu \mathrm{g}$ for pre-schoolchildren (0 to 59 months) \\
$120 \mu \mathrm{g}$ for schoolchildren (6 to 11 years) \\
$150 \mu \mathrm{g}$ for adults (12 years and above) \\
$250 \mu \mathrm{g}$ for pregnant and lactating women \\
\hline${ }^{\mathrm{a}}$ Derived from reference (5)
\end{tabular}

\subsubsection{Salt Iodization:}

Attempts have been made to improve iodine nutrition in areas of iodine deficiency using iodine supplementation through iodination of bread, water, sugar, oil etc. Although these routes of supplementation have been successful in some regions and communities, it appears that salt iodization is the simplest, cheapest, and most effective means of providing optimum iodine nutrition. Iodized oil preparations may be used when iodized salt is not widely available (10).

\subsubsection{Global IDD Situation:}

In 1991, the world health assembly (WHA) declared iodine deficiency as a major public health problem which should be eliminated by the year 2000. This goal had been endorsed in 1990 by world leaders when they met at the United Nations world summit for children. WHO and UNICEF recommended universal salt iodization (USI) for elimination of IDD in 1992 and 1993. Considerable progress has since been achieved, and it has been estimated that at least 75 million newborns entering the world in 2002 had been protected against the brain damage caused by iodine deficiency. In East Asia and Pacific, 20.8 million (16\%) of the global newborns and in South Asia 9 million, (14\%) were the highest numbers of newborns who were protected $(5,8)$.

Data made available by WHO shows that $31.5 \%$ (264 million) of schoolchildren and $30.6 \%$ (2000 million) of the general population worldwide have insufficient iodine intake (8). The greatest numbers of people with insufficient iodine intake are from Southeast Asia (504 million) and Europe (460 million). Figure 1 displays that household consumption of iodized salt is still less than $50 \%$ in the Eastern Mediterranean region and Europe (11).

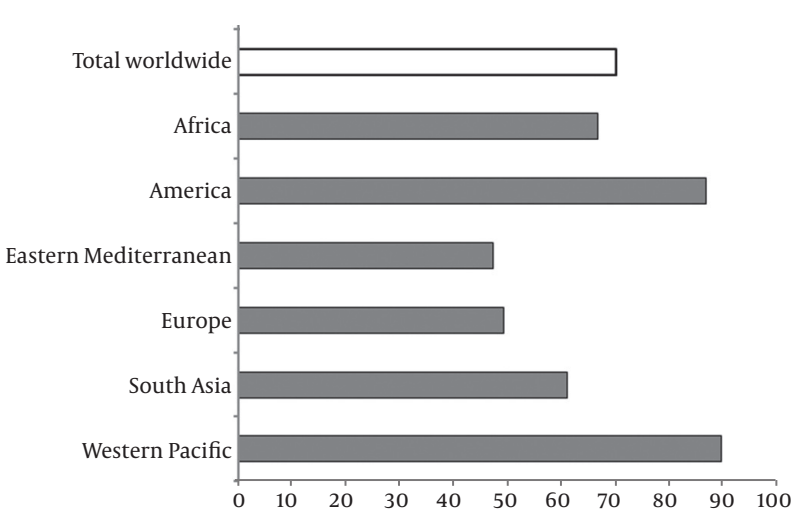

Figure 1. Proportion of Households with Access to Iodised Salt in Various Parts of the World; Adopted from UNICEF, 2007, Reference (5)

\subsubsection{Sustainable Elimination of Iodine Deficiency:}

Since 1990, there has been a tremendous progress in increasing the amount of adequately iodized salt, and as a result, many countries are now on the threshold of achieving IDD elimination; thus, the emphasis will shift to ensuring that the achievements are well sustained for all time. National ( $n=121)$ or large subnational $(n=31)$ UIC surveys have been done in 152 countries, representing $98 \%$ of the world's population $(12,13)$. In 2014 , iodine intake was adequate in 112 countries, deficient in 29 countries, and excessive in 11 countries (13). The number of iodine-sufficient countries increased from 67 to 112 during the last 10 years (13). Therefore, the main task in most countries will now be to sustain adequate iodine nutrition for their populations. A limitation of these data is that only a few countries (including IR Iran) have done national UIC surveys in pregnant women, a key target group. Large populous countries that are still iodine deficient include not only developing countries (e.g., Ethiopia, Morocco, and Mozambique) and countries in transition (e.g., Russia and Ukraine), but also several high-income countries (e.g., Denmark, Italy, and the UK) (13). Moreover, in several high-income countries, including the USA and Australia, iodine intakes have decreased in the past 30 years (14). Results of surveys suggest that many pregnant women in both developing and highincome countries, including the UK and the USA, have deficient iodine intakes (15), However, in some countries of the world, iodine supplementation has not been implemented and in many countries, the iodine nutrition supplementation in place is defective and does not reach the recommended levels of daily consumption. Therefore, in 2005 the world health assembly (WHA) once again passed another resolution to encourage the member states to strive for the elimination of iodine deficiency (16).

There are many important factors which influence the 
success and, in particular, the sustainability of an effective IDD elimination program (Box 2). As an example, The Islamic Republic of Iran (IR Iran), a developing country in nutrition transition, has been successful in conducting a sustainable program for more than 2 decades $(17,18)$. Changes in total goiter rate and median urinary iodine concentration in the past 2 decades in this country are shown in Figure 2.
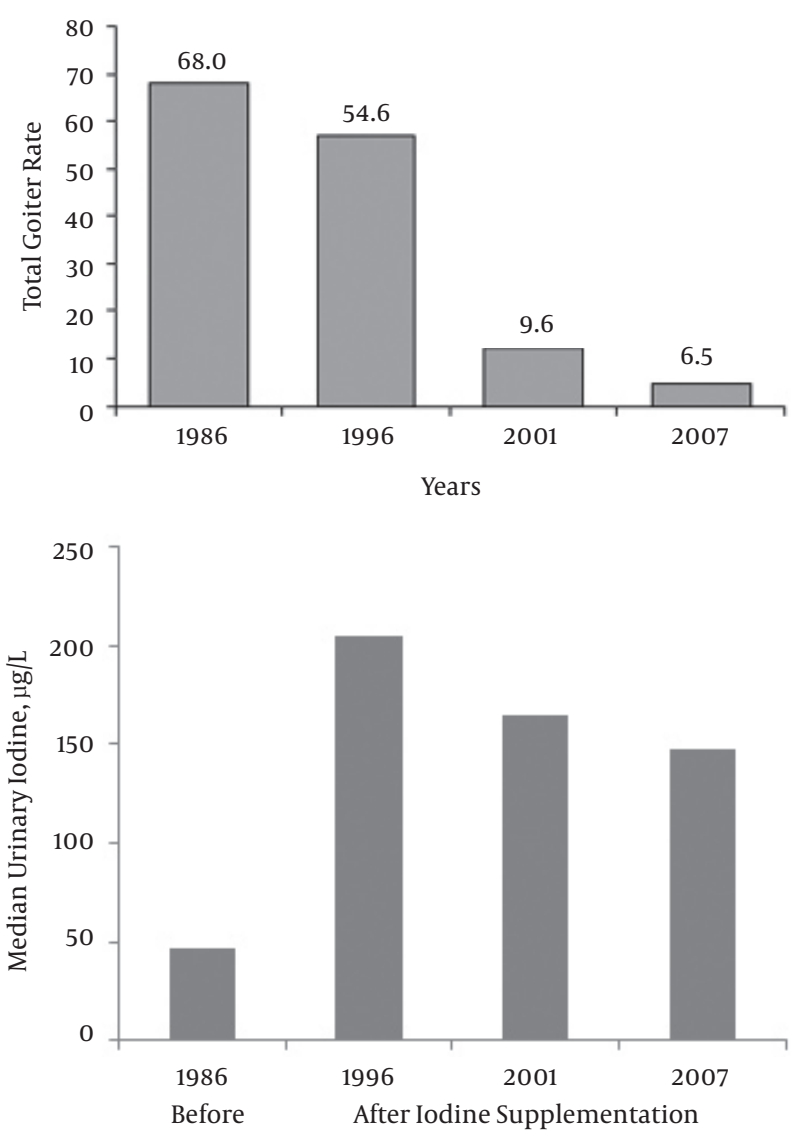

Figure 2. Total Goiter Rate (Panel A) and Median Urinary Iodine Conentration (Pane B) in 4 National Surveys in the IR Iran Before (1989) and Following Iodine Supplementation (1996, 2001 and 2007)

The lack of success in controlling and monitoring iodine deficiency in many countries presents a dismal picture. Proper estimations of iodine levels in salt factories, retailers, sellers, and households are not regularly done in many countries, and iodine measurement is performed only in a few countries affected by IDD, and others do not have supporting iodine laboratory network. Many countries fail to establish sustainable IDD control programs. The major obstacles faced today are as follow (19):

1-Legislation at government level is ineffective if no enforcement is in place. Many countries of the world lack effective legislation for USI, which has resulted in mild to moderate iodine deficiency and inadequate support for brain development in infants in these countries.

2- Political stability plays a major role in programming successful maintenance of a public health program. Many countries have not been successful in legislating, initiating, or successfully maintaining elimination of IDD, as their public health program has been damaged by political instability, change of officials, and health priorities and programs.

3- Current government policies in many countries favor decreased salt consumption in an attempt to reduce hypertension. This should be considered in programs of iodine supplementation through USI, and while advertising for low salt intake, $40 \mathrm{mg} / \mathrm{kg}$ (ppm) or precisely determined appropriate amounts of iodine should be added to the salt, taking into consideration the mean daily salt consumption of the specific populations. The logo should be "take less salt, but take only iodized salt".

In conclusion, iodine deficiency continues to be a major health problem in many countries. This is mainly due to the inefficient participation of the related policymakers, lack of function of national IDD committees, insufficient collaboration between health care providers, IDD experts, salt producers, communication specialists and consumer associates, and lack of efficient monitoring system for national country programs.

\subsubsection{Thyroid Disruptors}

Over the past 3 decades, there has been growing awareness that common environmental exposures including a variety of different groups of chemicals may affect thyroid function in humans. A classification of the chemicals that could disrupt thyroid hormone function is shown in Box $3(20,21)$. Neurodevelopment of the fetus and infant are more vulnerable to the permanent effects of thyroid disruptors. Adverse effects related to growth and reproduction may also appear in children and adolescents.

Some studies have shown the adverse effects of polychlorinated biphenyl (PCBs) on thyroid function. However, there are only few studies documented on thyroid-disrupting effects of other halogenated compounds, bisphenol A (BPA), UV filters, and phthalates (22-24).

The anions perchlorate, thiocyantae, and nitrate at pharmacologic doses may act as competitive inhibitors of the sodium iodide symporter, but their effects during environmental exposure are not clear (25).

Effects of compounds with direct actions on the thyroid hormone receptors are not yet well understood. Ingestion of high levels of isoflavons may inhibit TPO activity and cause goiter and hypothyroidism, in particular in 
Box 2. Vital Prerequisites for Success of IDD Control Programs

\begin{tabular}{l}
\hline Vital Prerequisites for Success of IDD Control Programs \\
\hline 1. Political commitment \\
\hline 2. Multiple sector involvement in planning and administration \\
\hline 3. Advocacy with the salt manufacturing and trading community \\
4. Information, education and communication (IEC) campaigns incorporating a social marketing approach \\
5. Economic and marketing incentives \\
6. Monitoring of iodine levels in salt \\
7. Legislation and enforcement \\
8. Contributions of external donors \\
9. Program monitoring \\
10. Leadership \\
11. National ownership for a sustainable program \\
\hline
\end{tabular}

Box 3. Classification of Thyroid Disruptors

\begin{tabular}{l}
\hline Classification of Thyroid Disruptors \\
\hline 1. Inhibition of Iodine Uptake \\
- Perchlorate \\
- Thiocyanates \\
- Nitrate \\
\hline 2. Direct action on thyroid hormone receptor \\
- Polychlorinated biphenyls polychlorinated biphenyls (PCBs) \\
- Bisphenol-A \\
- Triclosan \\
\hline 3. Displacement of T4 from transthyretin \\
- Polybrominateddiphenyl ethers \\
\hline - Hyproxylated PCBs \\
\hline 4. Inhibition of thyroperoxidase activity \\
\hline - Isoflavones \\
\hline 5. Activation of hepatic enzyme (decrease T4 half life) \\
- Orgachlorine pesticides \\
- Dioxins and furans \\
6. Other substances \\
- Styrenes, perfluorinated compounds, organophosphate pesticides, \\
sunscreens, lead \\
\hline
\end{tabular}

iodine deficient individuals (26). Quercetin is reported to be the most abundant flavonoid present in fruit and vegetables. It is also available as dietary supplements used as antioxidant, anti-proliferative, and anti-inflammatory agents. Excessive intake of quercetin has the potential of interfering with thyroid function. Quercetin acts as a thyroid disruptor by inhibiting thyroid-cell growth and iodide uptake due to down regulation of sodium/iodide symporter gene expression. A recent study revealed that quercetin may decrease the expression of thyroid peroxidase, thyroglobulin, and the thyrotropine receptor genes. Radioiodine uptake was significantly decreased after 14 days of quercetin treatment in rats, indicating the inhibitory effect of this substance on thyroid function (27).

Cyanide is one of the major environmental pollutants termed "thyroid disruptors". In one study, cyanide induced hyperthyroidism in male Wistar rats (28). Resveratrol, a polyphenol found in grapes and berries, which has antioxidant, antiproliferative and anti-inflammatory properties, causes inhibition of sodium/iodide symporter gene expression and function in the rat thyroid and may act as a thyroid disruptor, but its use as a supplement needs further evaluation (29).

Alterations of thyroid hormone secretion after longterm exposure to low doses of DDT through disruption of thyroxine secretion by thyrocytes have been reported. The DDT treatment in a low dose may induce similar changes observed during the development of hypothyroidism in conditions of iodine deficiency $(30,31)$.

In general, effects of the most potential thyroidal disruptors on thyroid function at environmental exposure levels remain unclear. Multiple exposures of disruptors could have additive or synergistic effects, data which should be confirmed by future studies. Unavoidable lifelong human exposure to mixtures of such environmental chemicals raises serious concerns about their potential adverse effects on thyroid function. Two recent articles have described some specific effects of disruptors on thyroid function of pregnant women and neurodevelopment 
of offsprings. In one study, higher end maternal urinary levels of perchlorate have been associated with the lowest IQs of offsprings (20). In another study, perfluroalkyl acids exposure has been accompanied with high serum TSH and low FT4 in TPOAb positive pregnant women (22). In the above-mentioned situations, where the evidence is not complete and there might be a suggestion of harm, the precautionary prevention may be used to avoid public health risks from processes or products (32).

\subsubsection{Risk Factors of Thyroid Autoimmunity}

Antibodies to thyroglobulin (TG) and thyroperoxidase (TPO) are present in both Hashimoto's thyroiditis and diffuse toxic goiter up to 7 years before the diagnosis (33). Lymphocyte infiltrates in the thyroid at autopsy have been reported in people with low levels of antibodies but without clinical disease (34). Many reasons have been proposed for the development of autoimmunity including thyroid autoimmunity, and understanding these factors may be useful in preventing occurrence of thyroid autoimmunity.

\subsubsection{Immunity Factors}

Immunity factors may include abnormal presentation of antigens caused by cell destruction, invasion of virus, abnormal antigen (degraded or denatured normal antigen) produced by a malignancy, or cell damage by viral attack, cross-reacting bacterial, or viral epitopes, e.g., Yersinia enter colitica $(35,36)$. Other etiologic or pathophysiologic process are as follow: Somatic mutation of a TCR rarely leading to a clone of self-reactive cells, inheritance of specific HLA, TCR, or other genes that code for antigen presentation proteins, aberrant $\mathrm{T}$ cell or B cell, failure of clonal deletion leaving self-reactive T cells, failure of normal maturation of immune system, allowing autoreactivity of fetal T and B cells, and polyclonal activation of $\mathrm{T}$ or B cells, leading to B cells producing self-reactive Ig, and somatic mutation of B cell Ig genes (36).

Regarding thyroid stimulating immunoglobulin (TSI), which is clonally restricted to the $\mathrm{V}$ gene, it has been suggested that Graves' disease may be due to the inheritance of an etiologically critical V gene encoding TSI. Also, as a primary event, epithelial cells (TECs) could express MHC class II molecules, and thereafter may function as APCs including antigens on their cell surface (36).

The coexistence of autoimmune thyroid disease (AITD) and other autoimmune diseases has suggested intrinsic abnormality in immune regulation. AITDs have associations with pernicious anemia. Circulating antigastric antibodies are present in $45 \%$ of the patients with autoimmune thyroiditis (37), and the reverse association is almost as strong (38). Approximately $14 \%$ of patients with pernicious anemia have hypothyroidism. The prevalence of pernicious anemia is also increased in patients with myxedema (39). Celiac disease is 3 times more common in patients with AITD; the autoantibodies against transglutaminase bind to thyroid cells and may play a role in thyroid disease pathogenesis (40). An associations of Sjogren's syndrome, systemic lupus erythematous (SLE), and rheumatoid arthritis with AITD have been reported $(41,42)$. There is also a high frequency of antibodies to nucleus, smooth muscle, and single-stranded DNA (26\% - 36\%) in AITD (43). A meta-analysis has reported an odds ratio of 1.7 for AITD in patients with multiple sclerosis (44). Type 1 diabetes mellitus, AITD, and Addison's disease occasionally coexist as the autoimmune polyglandular syndrome (APS) Type 2 (45), an autosomal dominant disorder, which may be associated with vitiligo, celiac disease, premature ovarian failure, myasthenia gravis, and chronic active hepatitis (46, 47). Autoimmune thyroid disease can be an infrequent feature of the much rarer APS Type 1 (48). There is no association between mutations in the AIRE (auto immune regulation) gene, which causes APS Type 1 and sporadic AITD (49).

\subsubsection{Environmental Factors Inducing Thyroid Autoimmunity}

Incomplete concordance seen in monozygotic twins or other siblings of individuals with AITD points to the strong evidence for an important role of environmental factors. The rise in childhood Graves' disease in Hong Kong, the steady rise in AITD in Calabria, Italy, and Austria, and the changes in the rates of histologically diagnosed Hashimoto's thyroiditis over a 124-year period (5053), point to the environmental influences in AITD incidence (50-53). Some studies have revealed a higher prevalence of thyroid autoimmunity in children raised in higher socioeconomic environments (54); the data are in line with the hygiene hypothesis that early exposure to infections may deviate the immune system from Th2 responses like allergy and autoimmunity.

Administration of IL-2 for the treatment of cancer (55), INF- $\alpha$, and other cytokines as well as antiretroviral therapy for HIV (56) may lead to the production of antithyroid antibodies and decreased thyroid function, which may be associated with a better tumor response. Interferon- $\beta$ b treatment has no significant adverse effect on AITD (57), however, long-term follow- up studies show that one fourth of patients with multiple sclerosis treated with this cytokine may develop AITD within the first year of treatment (58). Recurrence of thyrotoxicosis following attacks of allergic rhinitis (59) may be due to a rise in endogenous cytokines, and the association of raised IgE levels with newly diagnosed Graves' disease may be mediated by preferential Th2 activation (60).

Cigarette smoking is associated with Graves' disease 
and thyroid disease (61)although smoking is also reported to be associated with decreased incidence of hypothyroidism (62). Environmental tobacco smoke induces allergic sensitization in mice, which is associated with rise in production of Th2 cytokines but a decrease in Th1 cytokines by the respiratory tract (63). Modulation of cytokines may contribute to the worsening of ophthalmopathy with smoking and the opposite effect prevails in hypothyroidism and smoking exposure; a lower prevalence of thyroid autoantibodies in smokers was documented (64). Smoking cessation may induce a transient rise in AITD (65). Anatabine, an alkaloid found in tobacco, ameliorates experimental auto immune thyroiditis and reduces thyroglobulin (TG) antibody levels in humans with Hashimoto's thyroiditis (66).

More general environmental pollutants such as polychlorinated biphenyls (67) and pesticide use, in particular the fungicides Benomyl and Maneb/Mancozeb, have been associated with increased odds of developing thyroid dysfunction. Brazilians have shown that thyroid autoantibodies and Hashimoto's thyroiditis are more frequent in individuals living close to a petrochemical complex than in controls (68).

The role of dietary iodine has been established in animal models of AITD and evidence exists for a similar role in humans (69-72). It has been shown that although iodide may exacerbate thyroiditis in NOD mice, it did not affect the production of TSH-Rantibodies, indicating that change in Graves' disease may not be related to TSH-R. Iodine affects several aspects of the autoimmune response and also stimulates production of the chemokine CCL2, CXVL8, and CXCL14 in follicular cells (73). Therefore, iodine may induce AITD through upregulation of chemokines, which attract lymphocytes into the thyroid.

High dose selenium intake decreases TPOAb levels in women with AITD (74), as shown by the significant inverse association between $25(\mathrm{OH})$ D concentrations and TPOAb levels in Indians (75). AITD is also increased in same-sex marriage (76). The pathophysiology behind above findings is not clear.

The importance of stress in etiology of Graves' disease has been suggested (77). However, stress is not associated with TPOAb development in women (78). The pathway whereby stress may alter thyroid autoimmunity is unclear $(79,80)$. It has also been reported that moderate consumption of alcohol may have a protective effect with regards to AITD (81-83).

In summary, diversity of environmental factors and their possible effects on various genetic backgrounds have made it difficult to establish the relative importance of each factor in AITD. Viral and other infections are also considered as environmental factors (36).

\subsection{Primary Prevention of Thyroid Disease}

For many years, thyroidologists have been researching factors other than iodine that may affect thyroid health; of various factors that have been documented as having some effects on thyroid size and function, tobacco abuse and alcohol are thought to be more prominent.

\subsubsection{Tobacco Smoking}

Smoking is one of the leading preventable causes of various health derangements and death (84). Cigarette smoking introduces a large number of chemical substances to the human body that may affect the thyroid gland in different ways. The competitive inhibitory effect of thiocyanate on the sodium-iodine symporter (NIS) worsens iodine deficiency (85). Tobacco smoking causes a small decrease in serum TSH and an increase in serum free T4 (86). The effects of smoking on increased risk of Graves' hyperthyroidism, Graves' orbitopathy, in particular, are wellrecognized (87).

There are conflicting results regarding the association between smoking and hypothyroidism. It has been shown that incidence of hypothyroidism increases following cessation of cigarettes smoking; in addition, the prevalence of circulating TPOAb is lower in smokers as compared to nonsmokers (88), which is coupled with the appearance of thyroid antibodies in serum following smoking cessation (89) and accompanied by a transient rise in the incidence of overt autoimmune hypothyroidism (65). The exact pathophysiology of these changes has not been elucidated. Other studies have suggested that smokers may have a lower risk of thyroid cancer than nonsmokers (90).

It can be concluded that smoking cessation, which is recommended for community health, may lead to a decline in the overall prevalence of thyroid disease; however, populations may experience a shift in the type of thyroid disease (6).

\subsubsection{Alcohol Consumption}

Alcohol abuse leads to considerable morbidity and mortality. However, scientists from Denmark report that a reduction in the risk of Graves' disease with hyperthyroidism may be seen with moderate alcohol consumption (81), whereas others report conflicting results (91, 92); 3 studies found no effect of alcohol consumption in Graves' patients, while 1 showed a decrease risk in women but not in men.

\subsubsection{Thyroid Autoimmunity (Positive Thyroid Antibodies)}

It has been recommended that the presence of thyroid antibodies per se is not a reason to initiate thyroid hormone therapy. Despite the fact that the presence of antibodies alone can cause thyroid-related symptoms, few 
endocrinologists treat those with positive antibodies and TSH within the normal range who feel unwell. The presence of thyroid antibodies alone can affect fertility or the ability to maintain a pregnancy (93); therefore, some thyroidologists treat euthyroid pregnant women with positive TPOAb. Thyroid autoimmunity is characterized by infiltration of sensitized $\mathrm{T}$ lymphocytes in the thyroid gland and increased thyroid autoantibodies in the serum; it is an inherited defect in immune surveillance, which leads to alteration of presenting antigens in the gland, or abnormal regulation of immune responsiveness $(94,95)$. Clinical diagnosis of AITDs is usually made by the elevated levels of TSH-receptor antibodies (TSHRAb), antimicrosomal thyroid peroxidase antibodies (TPOAb), or anti-thyroglobulin antibodies (TgAb), with 90\% of patients with AITD having elevated antibody titers, which generally persist, although many of these patients are clinically and biochemically euthyroid.

Rates of positive $\mathrm{TgAb}$ and TPOAb in populations vary from $8 \%$ to $16 \%$ in various surveys $(96,97)$. In patients with subclinical hypothyroidism, TPOAb positivity helps predict progression to overt hypothyroidism. Approximately $4.3 \%$ and $2.6 \%$ of those with and without elevated TPOAb develop hypothyroidism yearly, respectively (98). Therefore, some professional societies and clinical endocrinologists endorse measurement of TPOAb in patients with subclinical hypothyroidism; assessment of TPOAb in patients with diffuse and firm goiter could identify autoimmune thyroiditis and predict any possibility of future hypothyroidism (99).

Patients with non-immunologic multinodular goiter rarely progress to hypothyroidism; however, it is important to separate patients who carry nodular variant of AITD because these patients may have be at a significant risk of hypothyroidism; in addition, they may need to have fineneedle aspiration biopsy to exclude malignancy (52).

Measurement of TSHRAb, which may act as a TSH agonist or antagonist, may be indicated under several conditions. The main indication of measurement of thyroid stimulating immunoglobulin(TSH) and/or TSH binding inhibitory immunoglobulin(TBI) is in pregnant women with a history of Graves' disease (irrespective of present thyroid function), as these tests predict fetal and neonatal hyperthyroidism (100); the time of measurement differed in various situations; in addition to the 28th weeks of pregnancy, earlier measurement of TSHRAb may also be indicated (101).

\section{Closing Remarks and Direction of Future Research}

A wide range of public health and medical considerations encounter the prevention of thyroid disease, a sub- ject which has received far too little attention worldwide from policymakers and medical professionals alike.

The main issue for primordial prevention of thyroid disease is proper iodine nutrition. Iodine deficiency is a major public health problem that is still prevalent in many countries of the world, in particular, in some European countries. Even in the so called "iodine sufficient" countries, iodine nutrition may be inadequate for pregnant women. Of factors affecting primary prevention, cigarette smoking has definite but variable effects on the thyroid economy. Successful campaigns against smoking may decrease benign thyroid disease and Graves' orbitopathy although this may be countered by increase in TPOAb, transient hypothyroidism, and a slight increase in the cases of thyroid cancer. Future researches are needed to find the best approach to prevent the presence of thyroid antibodies.

\section{Acknowledgments}

The authors would like to acknowledge Ms. Niloofar Shiva for critical editing of English grammar and syntax of the manuscript and Mrs. Tahereh Fakhimi for preparation of the manuscript.

\section{Footnotes}

Conflict of Interest: There is no conflict of interest.

Funding/Support: This research did not receive any specific grant from any funding agency in the public, commercial, or not-for-profit sector.

\section{References}

1. M N. Health protection from vision of traditional iranian medicine (in Persian). Tehran: Traditional Medicine Publ; 2012.

2. Bonita R, Beaglehole R, Kjellstrom T. Basic epidemiology. Geneva: World Health Organization; 2006.

3. Starfield B. Basic concepts in population health and health care.JEpidemiol Community Health. 2001;55(7):452-4. [PubMed: 11413173].

4. Murray CJ, Anderson B, Burstein R, Leach-Kemon K, Schneider M, Tardif A, et al. Development assistance for health: trends and prospects. Lancet. 2011;378(9785):8-10. doi: 10.1016/S01406736(10)62356-2. [PubMed: 21481450].

5. Hetzel B. The nature and magnitude of the iodine deficiency disorders. Towards the global elimination of brain damage due to iodine deficiency. New Delhi: Oxford University Press; 2004.

6. Cooper DS, Ridgway EC. Thoughts on prevention of thyroid disease in the United States. Thyroid. 2002;12(10):925-9. doi: 10.1089/105072502761016566. [PubMed: 12487775].

7. Zimmermann MB, Jooste PL, Pandav CS. Iodine-deficiency disorders. Lancet. 2008;372(9645):1251-62. doi: 10.1016/S0140-6736(08)61005-3. [PubMed: 18676011].

8. de Benoist B, McLean E, Andersson M, Rogers L. Iodine deficiency in 2007: global progress since 2003. Food Nutr Bull. 2008;29(3):195-202. doi: 10.1177/156482650802900305. [PubMed: 18947032]. 
9. W. H. O. Secretariat, Andersson M, de Benoist B, Delange F, Zupan J. Prevention and control of iodine deficiency in pregnant and lactating women and in children less than 2-years-old: conclusions and recommendations of the Technical Consultation. Public Health Nutr. 2007;10(12A):1606-11. doi: 10.1017/S1368980007361004. [PubMed: 18053287].

10. Azizi F. Iodized oil: its role in the management of iodine deficiency disorders. Int J Endocrinol Metab. 2007;2007(2):91-8.

11. WHO . Assessment of iodine deficiency disorders and monitoring their elimination: a guide for programme managers. Third, editor. Geneva: World Health Organization; 2007.

12. WHO. The WHO vitamin and mineral nutrition information system (VMNIS) on iodine deficiency disorders. Geneva: World Health Organization; 2009.

13. ICCIDD global network. . Website of the international council for the control of iodine deficiency disorders. [cited June 26]. Available from: http://www.iccidd.org.

14. Zimmermann MB. Symposium on 'Geographical and geological influences on nutrition': Iodine deficiency in industrialised countries. Proc Nutr Soc. 2010;69(1):133-43. doi: 10.1017/S0029665109991819. [PubMed: 19968908].

15. Caldwell KL, Pan Y, Mortensen ME, Makhmudov A, Merrill L, Moye J. Iodine status in pregnant women in the National Children's Study and in U.S. women (15-44 years), National Health and Nutrition Examination Survey 2005-2010. Thyroid. 2013;23(8):927-37. doi: 10.1089/thy.2013.0012. [PubMed: 23488982].

16. WHO . Sustaining the elimination of iodine deficiency disorders. Geneva: World Health Organization; 2005.

17. Delshad H, Amouzegar A, Mirmiran P, Mehran L, Azizi F. Eighteen years of continuously sustained elimination of iodine deficiency in the Islamic Republic of Iran: the vitality of periodic monitoring. Thyroid. 2012;22(4):415-21. doi: 10.1089/thy.2011.0156. [PubMed: 22409203].

18. Azizi F, Mehran L, Sheikholeslam R, Ordookhani A, Naghavi M, Hedayati M, et al. Sustainability of a well-monitored salt iodization program in Iran: marked reduction in goiter prevalence and eventual normalization of urinary iodine concentrations without alteration in iodine content of salt. J Endocrinol Invest. 2008;31(5):422-31. doi: 10.1007/BF03346386. [PubMed: 18560260].

19. World Health Organization . Elimination of iodine deficiency disorders: a manual for health workers. 35 , editor. Cairo: EMRO Technical Publications Series; 2008.

20. Bergman A, Heindel JJ, Jobling S, Kidd K, Zoeller TR. State of the science of endocrine disrupting chemicals 2012: summary for decision-makers Geneva: World Health Organization; 2013.

21. Braverman LE, Cooper DS. Werner \& Ingbar's the thyroid: a fundamental and clinical text. Philadelphia: Lippincott Williams \& Wilkins; 2012.

22. Boas M, Feldt-Rasmussen U, Main KM. Thyroid effects of endocrine disrupting chemicals. Mol Cell Endocrinol. 2012;355(2):240-8. doi: 10.1016/j.mce.2011.09.005. [PubMed: 21939731].

23. Romano ME, Webster GM, Vuong AM, Thomas Zoeller R, Chen A, Hoofnagle AN, et al. Gestational urinary bisphenol A and maternal and newborn thyroid hormone concentrations: the HOME Study.Environ Res. 2015;138:453-60. doi:10.1016/j.envres.2015.03.003. [PubMed: 25794847].

24. Wang T, Lu J, Xu M, Xu Y, Li M, Liu Y, et al. Urinary bisphenol a concentration and thyroid function in Chinese adults. Epidemiology. 2013;24(2):295-302. doi: 10.1097/EDE.0b013e318280e02f. [PubMed: 23337242].

25. Braverman LE, He X, Pino S, Cross M, Magnani B, Lamm SH, et al. The effect of perchlorate, thiocyanate, and nitrate on thyroid function in workers exposed to perchlorate long-term.JClin Endocrinol Metab. 2005;90(2):700-6. doi:10.1210/jc.2004-1821. [PubMed: 15572417].

26. Messina M, Redmond G. Effects of soy protein and soybean isoflavones on thyroid function in healthy adults and hypothyroid patients: a review of the relevant literature. Thyroid. 2006;16(3):24958. doi: 10.1089/thy.2006.16.249. [PubMed:16571087].

27. Giuliani C, Bucci I, Di Santo S, Rossi C, Grassadonia A, Piantelli M, et al. The flavonoid quercetin inhibits thyroid-restricted genes expression and thyroid function. Food Chem Toxicol. 2014;66:23-9. doi: 10.1016/j.fct.2014.01.016. [PubMed: 24447974].

28. Daniel AT, Adekilekun TA, Adewale MA, Adekemi AT. Cyanideinduced hyperthyroidism in male Wistar rats. Niger Med J. 2014;55(3):246-9. doi: 10.4103/0300-1652.132060. [PubMed: 25013258].

29. Giuliani C, Bucci I, Di Santo S, Rossi C, Grassadonia A, Mariotti M, et al. Resveratrol inhibits sodium/iodide symporter gene expression and function in rat thyroid cells. PLoS One. 2014;9(9):107936. doi: 10.1371/journal.pone.0107936. [PubMed: 25251397].

30. Iaglova NV, Iaglov VV. [Alteration of thyroid hormone secretion after long-term exposure to low doses of endocrine disruptor DDT]. Biomed Khim. 2014;60(6):655-60. [PubMed: 25552505].

31. Yaglova NV, Yaglov VV. Changes in thyroid status of rats after prolonged exposure to low dose dichlorodiphenyltrichloroethane. Bull Exp Biol Med. 2014;156(6):760-2. doi: 10.1007/s10517-014-2443-y. [PubMed: 24824690].

32. Martuzzi M, Tickner JA. The precautionary principle: protecting public health, the environment and the future of our children. Copenhagen: WHO; 2004.

33. Hutfless S, Matos P, Talor MV, Caturegli P, Rose NR. Significance of prediagnostic thyroid antibodies in women with autoimmune thyroid disease. J Clin Endocrinol Metab. 2011;96(9):E1466-71. doi: 10.1210/jc.2011-0228. [PubMed: 21715532].

34. Nielsen CH, Leslie RG, Jepsen BS, Kazatchkine MD, Kaveri SV, Fischer E. Natural autoantibodies and complement promote the uptake of a self antigen, human thyroglobulin, by B cells and the proliferation of thyroglobulin-reactive CD4(+) T cells in healthy individuals. Eur J Immunol. 2001;31(9):2660-8. [PubMed: 11536164].

35. Lidman K, Eriksson U, Norberg R, Fagraeus A. Indirect immunofluorescence staining of human thyroid by antibodies occurring in Yersinia enterocolitica infections. Clin Exp Immunol. 1976;23(3):42935. [PubMed: 780011].

36. Weetman A, DeGroot LJ. Autoimmunity to the thyroid gland. In: DeGroot LJ, Chrousos G, Dungan K, Feingold KR, Grossman A, Hershman JM, editors. Endocrinology of Pregnancy. ; 2000. .

37. Irvine WJ, Davies SH, Teitelbaum S, Delamore IW, Williams AW. The clinical and pathological significance of gastric parietal cell antibody. Ann N Y Acad Sci. 1965;124(2):657-91. [PubMed: 5320501].

38. Doniach D, Ro Itt IM, Taylor KB. Autoimmune phenomena in pernicious anaemia. Serological overlap with thyroiditis, thyrotoxicosis, and systemic lupus erythematosus. BrMed J. 1963;1(5342):1374-9. [PubMed: 14028630].

39. Tudhope GR, Wilson GM. Deficiency of vitamin B12 in hypothyroidism. Lancet. 1962;1(7232):703-6. [PubMed:13923015].

40. Naiyer AJ, Shah J, Hernandez L, Kim SY, Ciaccio EJ, Cheng J, et al. Tissue transglutaminase antibodies in individuals with celiac disease bind to thyroid follicles and extracellular matrix and may contribute to thyroid dysfunction. Thyroid. 2008;18(11):1171-8. doi: 10.1089/thy.2008.0110. [PubMed: 19014325].

41. Buchanan WW, Crooks J, Alexander WD, Koutras DA, Wayne EJ, Gray KG. Association of Hashimoto's thyroiditis and rheumatoid arthritis. Lancet. 1961;277(7171):245-8.

42. Mulhern LM, Masi AT, Shulman LE. Hashimoto's disease. A search for associated disorders in 170 clinically detected cases. Lancet. 1966;2(7462):508-11. [PubMed: 4161707].

43. Morita S, Arima T, Matsuda M. Prevalence of nonthyroid specific autoantibodies in autoimmune thyroid diseases. J Clin Endocrinol Metab. 1995;80(4):1203-6. doi: 10.1210/jcem.80.4.7714090. [PubMed: 7714090].

44. Dobson R, Giovannoni G. Autoimmune disease in people with mul- 
tiple sclerosis and their relatives: a systematic review and metaanalysis. J Neurol. 2013;260(5):1272-85. doi: 10.1007/s00415-012-67901. [PubMed: 23315260].

45. Neufeld M, Maclaren NK, Blizzard RM. Two types of autoimmune Addison's disease associated with different polyglandular autoimmune (PGA) syndromes. Medicine (Baltimore). 1981;60(5):355-62. [PubMed: 7024719].

46. Falorni A, Laureti S, Santeusanio F. Autoantibodies in autoimmune polyendocrine syndrome type II. Endocrinol Metab Clin North Am. 2002;31(2):369-89. [PubMed: 12092456] vii.

47. Weetman AP. Autoimmunity to steroid-producing cells and familial polyendocrine autoimmunity. Baillieres Clin Endocrinol Metab. 1995;9(1):157-74. [PubMed: 7726795].

48. Ahonen P, Myllarniemi S, Sipila I, Perheentupa J. Clinical variation of autoimmune polyendocrinopathy-candidiasis-ectodermal dystrophy (APECED) in a series of 68 patients. $N$ Engl J Med. 1990;322(26):1829-36. doi:10.1056/NEJM199006283222601. [PubMed: 2348835].

49. Nithiyananthan R, Heward JM, Allahabadia A, Barnett AH, Franklyn JA, Gough SC. A heterozygous deletion of the autoimmune regulator (AIRE1) gene, autoimmune thyroid disease, and type 1 diabetes: no evidence for association. J Clin Endocrinol Metab. 2000;85(3):1320-2. doi: 10.1210/jcem.85.3.6465. [PubMed:10720083].

50. Benvenga S, Trimarchi F. Changed presentation of Hashimoto's thyroiditis in North-Eastern Sicily and Calabria (Southern Italy) based on a 31-year experience. Thyroid. 2008;18(4):429-41. doi: 10.1089/thy.2007.0234. [PubMed: 18399767].

51. Caturegli P, De Remigis A, Chuang K, Dembele M, Iwama A, Iwama S. Hashimoto's thyroiditis: celebrating the centennial through the lens of the Johns Hopkins hospital surgical pathology records. Thyroid. 2013;23(2):142-50. doi: 10.1089/thy.2012.0554. [PubMed: 23151083].

52. Ott J, Meusel M, Schultheis A, Promberger R, Pallikunnel SJ, Neuhold $\mathrm{N}$, et al. The incidence of lymphocytic thyroid infiltration and Hashimoto's thyroiditis increased in patients operated for benign goiter over a 31-year period. Virchows Arch. 2011;459(3):277-81. doi: 10.1007/s00428-011-1130-x. [PubMed: 21786141].

53. Wong GW, Cheng PS. Increasing incidence of childhood Graves' disease in Hong Kong: a follow-up study. Clin Endocrinol (Oxf). 2001;54(4):547-50. [PubMed: 11318792].

54. Kondrashova A, Viskari H, Haapala AM, Seiskari T, Kulmala P, Ilonen J, et al. Serological evidence of thyroid autoimmunity among schoolchildren in two different socioeconomic environments. J Clin Endocrinol Metab. 2008;93(3):729-34. doi: 10.1210/jc.2007-1644. [PubMed: 18073310].

55. Atkins MB, Mier JW, Parkinson DR, Gould JA, Berkman EM, Kaplan MM. Hypothyroidism after treatment with interleukin-2 and lymphokine-activated killer cells. N Engl J Med. 1988;318(24):1557-63. doi: 10.1056/NEJM198806163182401. [PubMed: 3259674].

56. Gilquin J, Viard JP, Jubault V, Sert C, Kazatchkine MD. Delayed occurrence of Graves' disease after immune restoration with HAART. Highly active antiretroviral therapy. Lancet. 1998;352(9144):1907-8. [PubMed: 9863795].

57. Durelli L, Ferrero B, Oggero A, Verdun E, Ghezzi A, Montanari E, et al. Thyroid function and autoimmunity during interferon beta- $1 \mathrm{~b}$ treatment: a multicenter prospective study. J Clin Endocrinol Metab. 2001;86(8):3525-32. doi: 10.1210/jcem.86.8.7721. [PubMed: 11502774].

58. Caraccio N, Dardano A, Manfredonia F, Manca L, Pasquali L, Iudice A, et al. Long-term follow-up of 106 multiple sclerosis patients undergoing interferon-beta $1 \mathrm{a}$ or $1 \mathrm{~b}$ therapy: predictive factors of thyroid disease development and duration. J Clin Endocrinol Metab. 2005;90(7):4133-7. doi: 10.1210/jc.2004-2326. [PubMed:15811929].

59. Hidaka Y, Amino N, Iwatani Y, Itoh E, Matsunaga M, Tamaki H. Recurrence of thyrotoxicosis after attack of allergic rhinitis in patients with Graves' disease. J Clin Endocrinol Metab. 1993;77(6):1667-70. doi: 10.1210/jcem.77.6.8263157. [PubMed: 8263157].
60. Yamada T, Sato A, Komiya I, Nishimori T, Ito Y, Terao A, et al. An elevation of serum immunoglobulin E provides a new aspect of hyperthyroid Graves' disease. J Clin Endocrinol Metab. 2000;85(8):2775-8. doi: 10.1210/jcem.85.8.6741. [PubMed: 10946880].

61. Bartalena L, Bogazzi F, Tanda ML, Manetti L, Dell'Unto E, Martino E. Cigarette smoking and the thyroid. EurJEndocrinol. 1995;133(5):50712. [PubMed: 7581977].

62. Andersen SL, Olsen J, Wu CS, Laurberg P. Smoking reduces the risk of hypothyroidism and increases the risk of hyperthyroidism: evidence from 450,842 mothers giving birth in Denmark. Clin Endocrinol (Oxf). 2014;80(2):307-14. doi: 10.1111/cen.12279. [PubMed: 23808881].

63. Rumold R, Jyrala M, Diaz-Sanchez D. Secondhand smoke induces allergic sensitization in mice. J Immunol. 2001;167(8):4765-70. [PubMed: 11591808].

64. Belin RM, Astor BC, Powe NR, Ladenson PW. Smoke exposure is associated with a lower prevalence of serum thyroid autoantibodies and thyrotropin concentration elevation and a higher prevalence of mild thyrotropin concentration suppression in the third National Health and Nutrition Examination Survey (NHANES III) J Clin Endocrinol Metab. 2004;89(12):6077-86. doi: 10.1210/jc.20040431. [PubMed: 15579761].

65. Carle A, Bulow Pedersen I, Knudsen N, Perrild H, Ovesen L, Banke Rasmussen L, et al. Smoking cessation is followed by a sharp but transient rise in the incidence of overt autoimmune hypothyroidism - a population-based, case-control study. Clin Endocrinol (Oxf). 2012;77(5):764-72. doi:10.1111/j.1365-2265.2012.04455.x. [PubMed: 22651374].

66. Schmeltz LR, Blevins TC, Aronoff SL, Ozer K, Leffert JD, Goldberg MA, et al. Anatabine supplementation decreases thyroglobulin antibodies in patients with chronic lymphocytic autoimmune (Hashimoto's) thyroiditis: a randomized controlled clinical trial J Clin Endocrinol Metab. 2014;99(1):E137-42. doi: 10.1210/jc.2013-2951. [PubMed: 24178792].

67. Gu JY, Qian CH, Tang W, Wu XH, Xu KF, Scherbaum WA, et al. Polychlorinated biphenyls affect thyroid function and induce autoimmunity in Sprague-Dawley rats. Horm Metab Res. 2009;41(6):471-4 [PubMed: 19530273].

68. de Freitas CU, Grimaldi Campos RA, Rodrigues Silva MA, Panachao MR, de Moraes JC, Waissmann W, et al. Can living in the surroundings of a petrochemical complex be a risk factor for autoimmune thyroid disease? Environ Res. 2010;110(1):112-7. doi 10.1016/j.envres.2009.10.009. [PubMed: 19913221].

69. Goldner WS, Sandler DP, Yu F, Hoppin JA, Kamel F, Levan TD. Pesticide use and thyroid disease among women in the Agricultural Health Study. Am J Epidemiol. 2010;171(4):455-64. doi: 10.1093/aje/kwp404. [PubMed: 20061368].

70. Papanastasiou L, Alevizaki M, Piperingos G, Mantzos E, TseleniBalafouta S, Koutras DA. The effect of iodine administration on the development of thyroid autoimmunity in patients with nontoxic goiter. Thyroid. 2000;10(6):493-7. doi: 10.1089/thy.2000.10.493. [PubMed: 10907993].

71. Teng X, Shan Z, Chen Y, Lai Y, Yu J, Shan L, et al. More than adequate iodine intake may increase subclinical hypothyroidism and autoimmune thyroiditis: a cross-sectional study based on two Chinese communities with different iodine intake levels. Eur J Endocrinol. 2011;164(6):943-50. doi:10.1530/EJE-10-1041. [PubMed: 21444648].

72. Zois C, Stavrou I, Svarna E, Seferiadis K, Tsatsoulis A. Natural course of autoimmune thyroiditis after elimination of iodine deficiency in northwestern Greece. Thyroid. 2006;16(3):289-93. doi: 10.1089/thy.2006.16.289. [PubMed: 16571092].

73. Yamazaki K, Tanigawa K, Suzuki K, Yamada E, Yamada T, Takano K, et al. Iodide-induced chemokines and genes related to immunological function in cultured human thyroid follicles in the presence of thyrotropin. Thyroid. 2010;20(1):67-76. doi: 10.1089/thy.2009.0242. 
[PubMed: 20025541].

74. Turker O, Kumanlioglu K, Karapolat I, Dogan I. Selenium treatment in autoimmune thyroiditis: 9-month follow-up with variable doses. J Endocrinol. 2006;190(1):151-6. doi: 10.1677/joe.1.06661. [PubMed: 16837619].

75. Goswami R, Marwaha RK, Gupta N, Tandon N, Sreenivas V, Tomar N, et al. Prevalence of vitamin D deficiency and its relationship with thyroid autoimmunity in Asian Indians: a community-based survey. Br J Nutr. 2009;102(3):382-6. doi: 10.1017/S0007114509220824. [PubMed: 19203420].

76. Frisch M, Nielsen NM, Pedersen BV. Same-sex marriage, autoimmune thyroid gland dysfunction and other autoimmune diseases in Denmark 1989-2008. Eur J Epidemiol. 2014;29(1):63-71. doi: 10.1007/s10654-013-9869-9. [PubMed: 24306355].

77. Chiovato L, Pinchera A. Stressful life events and Graves' disease. Eur J Endocrinol. 1996;134(6):680-2. [PubMed: 8766933].

78. Strieder TG, Prummel MF, Tijssen JG, Brosschot JF, Wiersinga WM. Stress is not associated with thyroid peroxidase autoantibodies in euthyroid women. Brain Behav Immun. 2005;19(3):203-6. doi: 10.1016/j.bbi.2004.07.003. [PubMed: 15797308].

79. Saint-Mezard P, Chavagnac C, Bosset S, Ionescu M, Peyron E, Kaiserlian D, et al. Psychological stress exerts an adjuvant effect on skin dendritic cell functions in vivo. J Immunol. 2003;171(8):4073-80. [PubMed: 14530328].

80. Steinman L. Elaborate interactions between the immune and nervous systems. Nat Immunol. 2004;5(6):575-81. doi: 10.1038/ni1078. [PubMed: 15164017].

81. Carle A, Bulow Pedersen I, Knudsen N, Perrild H, Ovesen L, Rasmussen LB, et al. Graves' hyperthyroidism and moderate alcohol consumption: evidence for disease prevention. Clin Endocrinol (Oxf). 2013;79(1):111-9. doi: 10.1111/cen.12106. [PubMed: 23170908].

82. Carle A, Pedersen IB, Knudsen N, Perrild H, Ovesen L, Rasmussen $\mathrm{LB}$, et al. Moderate alcohol consumption may protect against overt autoimmune hypothyroidism: a population-based case-control study. Eur J Endocrinol. 2012;167(4):483-90. doi: 10.1530/EJE-12-0356. [PubMed: 22802427].

83. Effraimidis G, Tijssen JG, Wiersinga WM. Alcohol consumption as a risk factor for autoimmune thyroid disease: a prospective study. Eur Thyroid J. 2012;1(2):99-104. doi: 10.1159/000338920. [PubMed: 24783003].

84. Asaria P, Chisholm D, Mathers C, Ezzati M, Beaglehole R. Chronic disease prevention: health effects and financial costs of strategies to reduce salt intake and control tobacco use. Lancet. 2007;370(9604):2044-53. doi: 10.1016/S0140-6736(07)61698-5. [PubMed: 18063027].

85. Laurberg P, Nohr SB, Pedersen KM, Fuglsang E. Iodine nutrition in breast-fed infants is impaired by maternal smoking. J Clin Endocrinol Metab. 2004;89(1):181-7. doi: 10.1210/jc.2003-030829. [PubMed: 14715847].

86. Knudsen N, Bulow I, Laurberg P, Perrild H, Ovesen L, Jorgensen T. High occurrence of thyroid multinodularity and low occurrence of subclinical hypothyroidism among tobacco smokers in a large population study. J Endocrinol. 2002;175(3):571-6. [PubMed:12475368].

87. Prummel MF, Wiersinga WM. Smoking and risk of Graves' disease. JAMA. 1993;269(4):479-82. [PubMed: 8419666].

88. Pedersen IB, Laurberg P, Knudsen N, Jorgensen T, Perrild H, Ovesen $\mathrm{L}$, et al. Smoking is negatively associated with the presence of thyroglobulin autoantibody and to a lesser degree with thyroid perox- idase autoantibody in serum: a population study. Eur J Endocrinol. 2008;158(3):367-73. doi: 10.1530/EJE-07-0595. [PubMed: 18299471].

89. Effraimidis G, Tijssen JG, Wiersinga WM. Discontinuation of smoking increases the risk for developing thyroid peroxidase antibodies and/or thyroglobulin antibodies: a prospective study. $J$ Clin Endocrinol Metab. 2009;94(4):1324-8. doi: 10.1210/jc.2008-1548. [PubMed: 19141579].

90. Kreiger N, Parkes R. Cigarette smoking and the risk of thyroid cancer. Eur J Cancer. 2000;36(15):1969-73. [PubMed: 11000579].

91. Holm IA, Manson JE, Michels KB, Alexander EK, Willett WC, Utiger RD. Smoking and other lifestyle factors and the risk of Graves' hyperthyroidism. Arch Intern Med. 2005;165(14):1606-11. doi: 10.1001/archinte.165.14.1606. [PubMed: 16043678].

92. Winsa B, Adami HO, Bergstrom R, Gamstedt A, Dahlberg PA, Adamson U, et al. Stressful life events and Graves' disease. Lancet. 1991;338(8781):1475-9. [PubMed: 1683917].

93. Negro R, Stagnaro-Green A. Thyroid autoantibodies, preterm birth, and miscarriage. BMJ. 2011;342:d2260. doi: 10.1136/bmj.d2260. [PubMed: 21558124].

94. Ban Y, Greenberg DA, Davies TF, Jacobson E, Concepcion E, Tomer Y. 'Linkage analysis of thyroid antibody production: evidence for shared susceptibility to clinical autoimmune thyroid disease. J Clin Endocrinol Metab. 2008;93(9):3589-96. doi: 10.1210/jc.2008-0364. [PubMed: 18559906].

95. Menconi F, Monti MC, Greenberg DA, Oashi T, Osman R, Davies TF, et al. Molecular amino acid signatures in the MHC class II peptidebinding pocket predispose to autoimmune thyroiditis in humans and in mice. Proc Natl Acad Sci U S A. 2008;105(37):14034-9. doi: 10.1073/pnas.0806584105. [PubMed: 18779568].

96. Amouzegar A, Gharibzadeh S, Kazemian E, Mehran L, Tohidi M, Azizi F. The Prevalence, Incidence and Natural Course of Positive Antithyroperoxidase Antibodies in a Population-Based Study: Tehran Thyroid Study. PLoS One. 2017;12(1):0169283. doi: 10.1371/journal.pone.0169283. [PubMed: 28052092].

97. Hollowell JG, Staehling NW, Flanders WD, Hannon WH, Gunter EW, Spencer CA, et al. Serum TSH, T(4), and thyroid antibodies in the United States population (1988 to 1994): National Health and Nutrition Examination Survey (NHANES III). J Clin Endocrinol Metab. 2002;87(2):489-99. doi:10.1210/jcem.87.2.8182. [PubMed: 11836274].

98. Huber G, Staub JJ, Meier C, Mitrache C, Guglielmetti M, Huber P, et al. Prospective study of the spontaneous course of subclinical hypothyroidism: prognostic value of thyrotropin, thyroid reserve, and thyroid antibodies. J Clin Endocrinol Metab. 2002;87(7):3221-6. doi: 10.1210/jcem.87.7.8678. [PubMed: 12107228].

99. Kubota S, Fujiwara M, Hagiwara H, Tsujimoto N, Takata K, Kudo T, et al. Multiple thyroid cysts may be a cause of hypothyroidism in patients with relatively high iodine intake. Thyroid. 2010;20(2):205-8. doi: 10.1089/thy.2009.0264. [PubMed: 20151828].

100. Fu J, Jiang Y, Liang L, Zhu H. Risk factors of primary thyroid dysfunction in early infants born to mothers with autoimmune thyroid disease. Acta Paediatr. 2005;94(8):1043-8. doi: 10.1080/08035250510033906. [PubMed: 16188847].

101. Laurberg P, Nygaard B, Glinoer D, Grussendorf M, Orgiazzi J. Guidelines for TSH-receptor antibody measurements in pregnancy: results of an evidence-based symposium organized by the European Thyroid Association. Eur J Endocrinol. 1998;139(6):584-6. [PubMed: 9916861]. 